services in preventing admission with different diagnostic categories (Fenton et al, 1982). Such variations may be due to a range of factors, such as variations in working practices, skill mix. referral patterns, availability of other community resources and accommodation, and the possibility of higher levels of disturbance in psychotic inner-city patients.

More detailed research is clearly required in order to investigate more precisely which behaviours and symptoms identified at assessment are predictive of future outcomes in terms of service provision; broad diagnostic categories being a blunt instrument in this regard.

\section{References}

Burns, T. BeArdsmore, A., Bhat, A. V., et al (1993) A controlled trial of home-based acute psychiatric services. I: Clinical and social outcome. British Journal of Psychiatry, 163, 49-54.

Dean, C.. Philups. J., Gadd, E., et al (1993) Comparison of community based service with hospital based service for people with acute. severe psychiatric illness. British Medical Journal, 307, 473-476.

Fenton, F., Tessier, L., Struening, E., et al (1982) Home and Hospital Psychiatric Treatment. London: Croom Helm.
Hoult, J., Rosen. A. \& ReYNolds, I. (1984) Community orientated treatment compared to psychiatric hospital orientated treatment. Social Science and Medicine, 8. 11. 1005-1010.

JoHNSON. S. (1997) London's Mental Health: A Report to the King's Fund Commission. London: King's Fund.

Mujien, M.. Marks, I. M. Connolly, J., et al (1992) The Daily Living Programme. Preliminary comparison of community versus hospital-based treatment for the seriously mentally ill facing emergency admission. British Journal of Psychiatry, 160, 379-384.

STEIN. L. I., TEST, M. A. \& MARX. A. J. (1975) Alternative to the hospital: a controlled study. American Joumal of Psychiatry, 132, 517-522.

TuFNEL. G., Bouras, N., WATSON. J. P.. et al (1985) Home assessment and treatment in a community psychiatric service. Acta Psychiatrica Scandinavica, 72, 20-28.

Tyrer. P.. MERson, S., ONYETt, S., et al (1994) The effect of personality disorder on clinical outcome. social networks and adjustment: a controlled clinical trial of psychiatric emergencies. Psychological Medicine, 24. 731-740.

WORLD HEALTH ORGaNization (1992) The Tenth Revision of the International Classification of Diseases and Related Health Problems (ICD-10). Geneva: WHO.

*Neil Brimblecombe, Team Leader, Dacorum Community Treatment Team, St Paul's, Slippers Hill, off Allandale, Hemel Hempstead, Herts HP2 5XY; and Geraldine H. O'Sullivan, Consultant Psychiatrist, Albany Lodge, St Albans, Herts

*Correspondence

\title{
Psychiatrists' attitudes to maintenance drug treatment in depression
}

\author{
Graham A. Jackson and Ishbel Maciver
}

\begin{abstract}
Alms and method The recurrence rate of major depression can be decreased by the use of maintenance drug treatment. This paper describes a survey of Scottish psychiatrists' attitudes to prescribing maintenance therapy. Questionnaires were sent to all Scottish psychiatrists at consultant and associate specialist grade.

Results It is evident that there are major differences in prescribing practices. How patients are managed would appear to depend on to whom they are referred. Clinical implications Psychiatrists do not appear to be practising evidence-based medicine in this context.
\end{abstract}

There is perhaps a need for greater consensus on the prevention of recurrence.

Until the late 1970 s, depression was generally described as an acute illness from which the patient was expected to return to a state of wellbeing. It was recognised that some individuals were prone to recurrent episodes, but it was felt that each of these should be treated as a discrete entity and that between these the individual would make a complete recovery. More recent 
research, however, has established the chronic nature of major depression, with relapse rates of up to $80 \%$ (Angst, 1992). Data from the Epidemiological Catchment Area Study indicated an $8 \%$ lifetime prevalence for depression in the general population and the risk for death by suicide as $15 \%$ in those who have been hospitalised for depression.

It is widely accepted that following resolution of depressive symptoms a 'continuation phase' of drug treatment of up to six months' duration is necessary in order to gain full control over an episode. However, in line with the increasing conceptualisation of major depression as a chronic disorder, research over recent years has provided increasing evidence that drug treatment continued beyond this point can effectively reduce the recurrence rate of major depression (and thus hopefully reduce the associated mortality rate). In this paper we use the term 'maintenance treatment' to describe this phase, although it is also described by certain authors as 'prophylactic treatment'.

Tricyclic antidepressants (Ayd, 1984: Kupfer et al, 1992), selective-serotonin reuptake inhibitors (Kupfer, 1993) and lithium (Medical Research Council Drug Trials Subcommittee, 1981) have all proved effective in this report.

Although there appears to be evidence that maintenance treatment reduces the risk of recurrence, the optimum length of therapy remains unknown. It has been stated that in patients with episodes that are less than two and a half years apart, treatment should be continued for at least five years (Kupfer et al, 1992), with some authors advocating life-long treatment in certain cases (Montgomery, 1996). In spite of this there is often a reluctance to prescribe long-term treatment to these patients or indeed for the patients to comply with long-term treatment. The reasons for this are many, including the experience of side-effects and doctors colluding with a patient's wish to stop medication in order to signify that he/she is better, i.e. that an episode of illness is over.

Similarly, the optimum dose required for maintenance treatment is unclear, although evidence would seem to point to a need for continuing medication at that dose which has been effective for the acute episode; reducing the dose may result in an increased risk of relapse (Frank et al, 1993).

\section{The study}

We carried out a survey of psychiatric consultants and associate specialists throughout Scotland looking at their practice in the prescribing of maintenance antidepressant therapy. A multiple-choice questionnaire was sent out using the Royal College of Psychiatrists' list of practising senior psychiatrists.
The questionnaire asked the respondents to state by choosing from a list of five durations of treatment, how long they would continue antidepressant therapy following resolution of depressive symptoms in the following circumstances: (1) after one episode of illness; (2) after second episode in one year; (3) after second episode in five years and (4) in people with a history of recurring unipolar illness.

We also asked whether they would continue the antidepressant at the same or at a lower dose as that which produced clinical improvement or indeed whether they would opt to change to another drug for maintenance treatment. Finally we asked respondents to rate five factors important in choosing a drug for this purpose.

\section{Findings}

Of 330 survey forms distributed, 209 replies were received, a response rate of $63.3 \%$. Of the respondents, $18(8.6 \%)$ were not involved in prescribing, and the following discussion relates to the 191 replies from prescribing doctors. It is likely that many of those who did not respond at all have retired or otherwise do not prescribe antidepressants commonly, e.g. psychotherapists, child psychiatrists.

Twenty-eight per cent of replies were from consultants of up to five years' standing. $26 \%$ of 5-10 years and $46 \%$ of more than 10 years, indicating a reasonable spread of seniority.

The responses to our questions about duration of treatment are summarised in Table 1. With regard to the dose of antidepressant used for maintenance treatment, $43 \%$ of respondents stated that it was their practice to continue with the same dose as that used to treat the acute phase, while $47 \%$ stated they would continue with the same drug at a lower dose; 3\% advocated changing to an alternative treatment.

We asked how doctors would follow-up people on maintenance therapy. About a fifth (19\%) had access to a specific affective disorders clinic: 75 (39\%) of doctors stated that they would follow-up all of those people via their psychiatric services, three $(2 \%)$ would refer all back to their general practitioner while $100(52 \%)$ would refer all but the most difficult back to their GP.

Our survey form also asked for an opinion on the importance of five factors in their choice of medicine. Proven efficacy and lack of side-effects were seen as most important, followed by safety in overdose. Availability of once daily dosage and, particularly, cost were seen as being much less important.

In an attempt to identify any differences in practice between newer consultants and their senior colleagues, we examined these results in relation to the length of time since appointment 
Table 1. Questionnaire responses regarding duration of treatment

\begin{tabular}{llllll}
\hline & Up to 6 months & Up to 1 year & Up to 2 years & Up to 5 years & Indefiniliely \\
\hline After first episode & $(95) 50 \%$ & $(68) 36 \%$ & $(16) 8 \%$ & - & \\
After second in l year & $(10) 5 \%$ & $(131) 69 \%$ & - & $(29) 15 \%$ & $(10) 5 \%$ \\
After second in 5 years & $(25) 13 \%$ & $(86) 45 \%$ & - & $(41) 21 \%$ & $(25) 13 \%$ \\
Known recurrent depression & - & $(29) 15 \%$ & $(29) 15 \%$ & $(34) 17 \%$ & $(78) 41 \%$ \\
\hline
\end{tabular}

as a consultant/associate specialist. The group in post for over 10 years were least likely to prescribe indefinite treatment and tended towards shortest duration of treatment. They were also more likely to favour lower doses of drugs for maintenance treatment. Those in post for 5-10 years were twice as likely as those in post over 10 years to prescribe indefinitely following a second episode in five years $110 / 46$ compared with 9/ 81); and 10 times as likely to prescribe antidepressants for over a year following a first episode of depression (10/46 compared with 2/ 81). There was little difference between all three groups in their prescribing habits in relation to known recurrent depression. The most recently appointed consultants (0-5 years in post) fell between the other two groups in relation to their duration of prescribing but they were more likely than the other groups to refer all but the most difficult people back to their GP. They were also more likely to work in mixed, as opposed to purely urban, practices.

\section{Comment}

Surveys are perhaps not the best way of assessing practice. People and their illnesses cannot be fitted into neat groups and psychiatrists ticking boxes in response to questions about strictly categorised situations may not provide an accurate reflection of how they respond when faced with the reality of an ill person. We make no mention of non-pharmacological methods of treatment, nor of diagnostic criteria for major depression; nor do we take account of the specific areas of expertise of individual doctors. However, this survey does give some idea of psychiatrists opinions on how recurring depression should be managed.

Perhaps one of the most striking findings in this study is the wide variation in practice between individual clinicians in their use of maintenance antidepressants. This is highlighted in the responses to the question of duration of treatment in known recurrent illness. Although $41 \%$ elected to treat indefinitely, the remainder of respondents were divided almost equally between treatment durations of up to one, two and five years.

In other categories even fewer were prepared to prescribe for the five-year minimum suggested by Kupfer et al (1992) although in general there was a tendency towards longer term prescribing with increasing frequency of recurrence.

Similarly, the group was almost equally divided on the question of dosage of drug for maintenance treatment. Current thinking is that once an acute episode of depression has been treated, maintenance therapy is most effective when it is continued at the same dose (Frank et al. 1993). However less than half of respondents stated that this was their practice.

It seems, therefore, that although there is a tendency towards prescribing in accordance with research findings, this is by no means universal.

It is also clear from these results that the follow-up of people who are being prescribed maintenance antidepressants is likely to have major resource implications if the trend towards longer term prescribing continues. This is likely to affect both psychiatric and primary care services in view of the choice of over half of our respondents to refer all but the most complicated cases back to their GPs for ongoing treatment.

It is interesting to note the differences in prescribing habits between consultants of 5-10 years' standing and their senior colleagues. One might postulate that the less experienced group are more likely to be influenced in their practice by new research findings, reflecting the increasing emphasis on evidence-based medicine over recent years. However, this is not borne out by the responses of the newest group of consultants ( $<5$ years). It would seem that their treatment of recurrent depression is more likely to follow traditional lines. Although this may be related to differences in the population being treated by this group (more likely to be rural), it may also reflect either a scepticism of new research or a tendency to be influenced by the practice of their most senior colleagues, by whom many are likely to have been trained.

Although there is clearly a need for further research into various aspects of treatment of recurrent depression, there is good evidence for the benefits of maintenance treatment on recurrence rates. The long-term use of antidepressant drugs must be balanced against the risk of sideeffects and the understandable reluctance of well people to take on-going medication. Additionally. the financial implications of treating large numbers of patients indefinitely with expensive drugs are likely to become apparent if this 
becomes standard practice. This study demonstrates a need for consensus among psychiatrists on how these patients should be managed. At present this appears to depend very much upon to whom they are referred, and many of us do not appear to be practising evidence-based medicine.

\section{Acknowledgements}

The costs of this survey were met by Dista Psychiatric Education Services. We would like to thank them and all the Scottish psychiatrists who took the time to respond to our survey.

\section{References}

ANGST, J. (1992) How recurrent and predictable is depressive illness? In Long Term Treatment of Depression (ed. S. Montgomery). pp 1-13. Chichester: John Wiley.

AYD, F. J. (1984) Long term treatment of chronic depression: 15 year experience with Doxepin $\mathrm{HCl}$. Journal of Clinical Psychiatry, 45. 39-46.
Frank, E., KuPfer, D. J., PEREl, J. M., et al (1993) Comparison of full dose versus half dose pharmacotherapy in the maintenance treatment of recurrent depression. Joumal of Affective Disorders. 27. 139-145.

KUPFER, D. J. (1993) Management of recurrent depression Journal of Clinical Psychiatry, 54 (suppl.), 29-33: 34-35.

-. Frank, E., PEREL, J. M., et al (1992) Flve year outcome for maintenance theraples in recurrent depression. Archives of General Psychiatry, 49, 769-773.

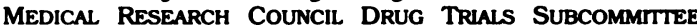
(1981) Continuation therapy with lithium and amitryptiline in unipolar depressive illness: a controlled clinical trial. Psychological Medicine, 11, 409.

MONTGOMERY. S. A. (1996) Efficacy in long term treatment of depression. Joumal of Clinical Psychiatry, 67 (suppl. 2). 24-30.

*Graham A. Jackson, Senior Registrar in Old Age Psychiatry, Hairmyres Hospital, Eaglesham Road, East Kilbride, Lanarkshire; Ishbel Maciver, Senior Registrar in Psychiatry, Douglas Inch Centre, 3 Woodside Terrace, Glasgow

*Correspondence

\title{
Psychopathy in Scotland
}

\author{
Martin Humphreys
}

Alms and method The aim was to examine why the legal category of psychopathic disorder does not appear in the Mental Health (Scotland) Act 1984 and to review selected literature relating to differences between prison and special hospital populations in Scotland from those elsewhere.

Results There is now some emerging evidence to suggest that the legislation north of the border might reflect the notion that there may be fewer people with psychopathic disorders in Scotland.

Clinical implications With devolution and the advent of a Scottish Parliament the Mental Health (Scotland) Act 1984 is likely to be reviewed. At that time it would be inappropriate to consider including 'psychopathic disorder' but some alternative to the current rather narrow definition of 'mental disorder' may be required.

There is still much debate over the possible need for reform of current mental health legislation. In considering this the status of the legal category of psychopathic disorder is almost always raised.
Reference has frequently been made to the fact that the term does not appear in the Scottish legislation. Are patients who would receive care and treatment under the 1983 Act being denied that right in Scotland?

Part I of the Mental Health Act 1983 defines the legal category of "psychopathic disorder" as

"a persistent disorder or disability of mind (whether or not including significant impairment of intelligence) which results in abnormally aggressive or seriously irresponsible conduct on the part of the person concerned".

There is, strictly speaking, no equivalent in the Mental Health (Scotland) Act 1984. What it does describe is a mental disorder which "is a persistent one manifested only by abnormally aggressive or seriously irresponsible conduct". The term "mental disorder" however, is previously defined as "mental illness or mental handicap however caused or manifested". It is therefore difficult to imagine what sort of clinical condition might fulfil all the necessary requirements of the 